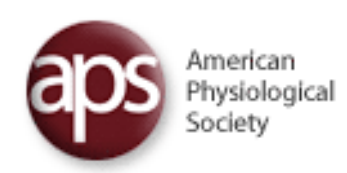

Journal of

Neurophysiology
PUBLISHED ARTICLE

ARCHIVES

SUBSCRIPTIONS

SUBMISSIONS

CONTACT US

\title{
Weak orientation and direction selectivity in lateral geniculate nucleus representing central vision in the gray squirrel Sciurus carolinensis
}

\author{
$\underline{\text { Julia B. Zaltsman }},{ }^{1}{ }^{\mathrm{J} \text {. Alexander Heimel, }},{ }^{4}$ and Stephen D. Van Hooser ${ }^{\bigotimes 1,2,3}$ \\ ${ }^{1}$ Department of Biology, Brandeis University, Waltham, Massachusetts; \\ ${ }^{2}$ Volen Center for Complex Systems, Brandeis University, Waltham, Massachusetts; \\ ${ }^{3}$ Sloan-Swartz Center for Theoretical Neurobiology, Brandeis University, Waltham, Massachusetts; and \\ ${ }^{4}$ Department of Cortical Structure and Function, Netherlands Institute for Neuroscience, Institute of the Royal Netherlands Academy of Arts \\ and Sciences, Amsterdam, The Netherlands \\ ${ }$ Corresponding author. \\ Address for reprint requests and other correspondence: S. D. Van Hooser, Brandeis Univ., 415 South St. MS008, Waltham, MA 02454 (e- \\ mail: vanhooser@brandeis.edu).
}

Received 2014 Jul 14; Accepted 2015 Feb 18.

Copyright (C) 2015 the American Physiological Society

\section{Abstract}

Classic studies of lateral geniculate nucleus (LGN) and visual cortex (V1) in carnivores and primates have found that a majority of neurons in LGN exhibit a center-surround organization, while V1 neurons exhibit strong orientation selectivity and, in many species, direction selectivity. Recent work in the mouse and the monkey has discovered previously unknown classes of orientation- and direction-selective neurons in LGN. Furthermore, some recent studies in the mouse report that many LGN cells exhibit pronounced orientation biases that are of comparable strength to the subthreshold inputs to V1 neurons. These results raise the possibility that, in rodents, orientation biases of individual LGN cells make a substantial contribution to cortical orientation selectivity. Alternatively, the size and contribution of orientation- or direction-selective channels from LGN to V1 may vary across mammals. To address this question, we examined orientation and direction selectivity in LGN and V1 neurons of a highly visual diurnal rodent: the gray squirrel. In the representation of central vision, only a few LGN neurons exhibited strong orientation or direction selectivity. Across the population, LGN neurons showed weak orientation biases and were much less selective for orientation compared with V1 neurons. Although direction selectivity was weak overall, LGN layers 3abc, which contain neurons that express calbindin, exhibited elevated direction selectivity index values compared with LGN layers 1 and 2. These results suggest that, for central visual fields, the contribution of orientation- and direction-selective channels from the LGN to V1 is small in the squirrel. As in other mammals, this small contribution is elevated in the calbindin-positive layers of the LGN

Keywords: motion, thalamocortical, thalamus, striate cortex, area 17, lateral geniculate body, lateral 
IN THE PRIMARY VISUAL CORTEX (V1) of all examined mammals, neurons exhibit orientation selectivity; that is, neurons exhibit a preferential response to stimuli (such as a bar of light) oriented at a particular angle (Hubel and Wiesel 1959, 1968; Girman et al. 1999; Ibbotson and Mark 2003; Van Hooser et al. 2005). Neurons in primary visual cortex of some mammals exhibit selectivity for stimulus direction of motion or simply direction selectivity, which indicates that the cell exhibits a preferential response to stimuli moving in one direction across the cell's receptive field (Gilbert 1977; Orban et al. 1986; Hawken et al. 1988; Weliky et al. 1996). In all mammals, the primary visual cortex receives projections from the retina via relay cells in the dorsal lateral geniculate nucleus (LGN) (Casagrande and Norton 1991).

Retinal ganglion cells provide input to LGN and other structures. For many decades, it was believed that the overwhelming majority of retinal ganglion cells that project to the LGN exhibited a center-surround

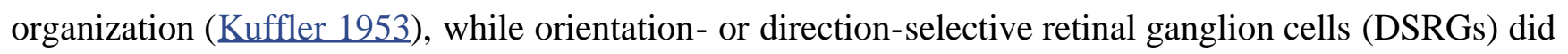
not project to LGN and instead projected to the superior colliculus (Michael 1972; Semm 1978; but see Stewart et al. 1971). Furthermore, classic studies in cat and monkey have shown that orientation selectivity and direction selectivity are much weaker in LGN compared with the primary visual cortex (Hubel and

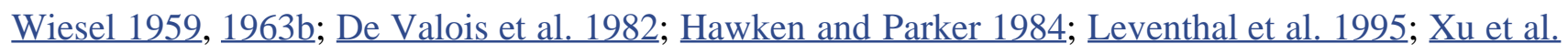
2002).

Recent work, and previous work in rabbits (Swadlow and Weyand 1985), has identified new populations of orientation-selective or direction-selective LGN neurons in regions of the LGN that express calbindin (Marshel et al. 2012; Cheong et al. 2013; Piscopo et al. 2013; Scholl et al. 2013; Zhao et al. 2013; CruzMartin et al. 2014). Some of these studies that were performed in mice have suggested that the overall orientation or direction bias provided to cortex might be different in mice compared with other species

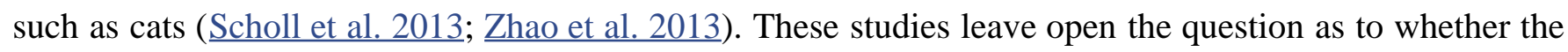
average orientation or direction tuning in rodent LGN cells is larger than in other mammals or rather if there is merely a minority of cells that are well tuned for orientation and direction in the LGN of all or most mammals.

The gray squirrel provides an opportunity to examine the laminar organization of orientation and direction selectivity in LGN of a highly visual rodent (Kaas et al. 1972a, $\underline{\text { b }}$ Jacobs et al. 1982; Blakeslee et al. 1988; Paolini and Sereno 1998). Gray squirrels have relatively high acuity vision ( vision for arboreal navigation and for predator avoidance. Importantly, they have a well-laminated LGN that features five layers that have been studied anatomically (Kaas et al. 1972b), physiologically ( $\underline{\text { Van }}$ Hooser et al. 2003), and molecularly (Felch and Van Hooser 2012).

Our results indicate that, in the central visual representation of the gray squirrel, orientation selectivity in the LGN is much weaker than the cortex and both structures exhibit only weak direction selectivity. While orientation selectivity did not vary significantly across the layers of the squirrel LGN, the differences in direction selectivity across the layers were significant. Overall, orientation angle preference was evenly distributed for cells in both the squirrel visual cortex and LGN, and we observed no evidence of anisotropy of orientation preferences and retinotopic location. These results are inconsistent with the idea that orientation selectivity in the cortex is simply inherited from individual LGN cells. This computation likely requires an additional layer of computation, such as the elongated colinear projections of center-surround LGN connections to cortex that are posited in Hubel and Wiesel's original model, (Hubel and Wiesel 


\section{MATERIALS AND METHODS}

The orientation and direction data from squirrel LGN presented here have never been published previously and were collected at the same time as the data from Van Hooser et al. (2003). We compare the tuning of LGN neurons to that observed in neurons in squirrel visual cortex by the same authors using the same software/hardware ( LGN and V1 by one of the authors using the same software (Van Hooser et al. 2013).

Surgical preparation. Adult gray squirrels of either sex weighting 475-700 g were prepared for single-unit recording using the methods described in Van Hooser et al. (2003) and Heimel et al. (2005). In brief, animals were initially anesthetized with a mixture of ketamine and acepromazine maleate $(90 \mathrm{mg} / \mathrm{ml}$ ketamine, $0.91 \mathrm{mg} / \mathrm{ml}$ acepromazine maleate, and $0.5 \mathrm{ml} / \mathrm{kg}$ initial dose $\mathrm{im}$ ). A femoral vein was cannulated for intravenous infusion, and a tracheostomy was performed for artificial administration of isoflurane anesthesia for the remainder of the experiment (0.5-2.0\% isoflurane in 50/50 oxygen/nitrous oxide). Respiration was provided by a rodent ventilator, with a 5-ml stroke volume operating at 35-90 strokes/min, adjusted to keep end-tidal $\mathrm{CO}_{2}$ at $4 \%$, measured with a Tidal Wave capnograph. The animal was mounted in a custom-made stereotaxic frame specifically designed to not obstruct frontal vision. Heart rate and the electroencephalogram (EEG) were recorded and displayed continuously. Rectal temperature was monitored and maintained at $38^{\circ} \mathrm{C}$ by a heating pad. Pupils were dilated with $1 \%$ atropine sulfate, contact lenses were inserted to prevent drying, and eyelids were held open with loose sutures. A small craniotomy was performed above the LGN (2 to $6.5 \mathrm{~mm}$ lateral from bregma and 0 to $5 \mathrm{~mm}$ posterior to bregma) or cortex (centered $3.5 \mathrm{~mm}$ lateral from begma, $6.5 \mathrm{~mm}$ posterior to bregma, $3 \times 3 \mathrm{~mm}$ window), the dura was resected, and the surface of the brain was digitally photographed for charting electrode penetration locations. Warm artificial cerebrospinal fluid was used to protect the brain and minimize pulsations; in cortex, 3\% agarose was used instead of artificial cerebrospinal fluid. Intravenous infusion of neuromuscular blockers (10 mg/ml gallamine triethoiodide, $0.5 \mathrm{ml} / \mathrm{h}$ ) was used to suppress spontaneous eye movements. After paralysis, heart rate and EEG were monitored carefully to ensure adequate anesthesia; isoflurane concentration was increased if spindle activity disappeared on the EEG or if the heart rate increased in response to a toe pinch. A mixture of $1 \%$ isoflurane was typically used to maintain the level of anesthesia. The location of the nasal bulb of each optic streak was charted after paralysis had taken effect. It was found that it was not necessary to adjust the focus of the eyes (Van Hooser et al. 2003). All procedures were approved by the Brandeis University Animal Care and Use Committee.

The surgical preparation and anesthesia used were identical for the LGN and V1 neurons reported here. The experiments were performed sequentially in the same 15-mo period by the same experimenters (J. A. Heimel and S. D. Van Hooser) with the same software and hardware, so we expect any differences observed to reflect actual differences between LGN and V1 rather than methodological differences.

Visual stimulation. Visual stimulation was provided by a gamma-corrected Samsung SyncMaster 900SL CRT monitor running custom-developed stimulation software (Van Hooser et al. 2003) using Matlab (The MathWorks, Natick, MA) and the Psychophysics Toolbox (Brainard 1997; Pelli 1997). Stimuli were shown at a distance of $57 \mathrm{~cm}$ from the eyes with a refresh rate of $120 \mathrm{~Hz}$. The same software and hardware configuration was used for both LGN and V1 recordings. 
Recording, data acquisition, and stimulation. The LGN was initially mapped with several penetrations using low-impedance microelectrodes (1 M $\Omega$; WPI, Sarasota, FL) as described in Van Hooser et al. (2003). Responses to handheld stimuli were mapped while monitoring neuronal activity on a loudspeaker. Layers 1 and 2 could be distinguished from layers 3abc because layers 1 and 2 typically gave very sustained responses, while layers 3abc were primarily transient. Transitions into and out of layers 2 and 3b were easily identified, as these layers respond to ipsilateral stimulation (Figure 1A). Typically, several penetrations were made to establish the locations of the different layers as accessed through the horizontal surface, which was photographed with a digital camera. For single unit recording, high-impedance microelectrodes (3-7 M $\Omega$; Thomas Recording, Giessen, Germany; or FHC, Bowdoin, ME) were coated with Di-I to aid histological identification (Snodderly and Gur 1995; DiCarlo et al. 1996) and introduced to the brain. Signals were amplified $\times 10,000$ with a headstage and amplifier (Multichannel Systems) and sampled digitally. A custom-developed multiple-window discriminator was used to isolate action potentials with Matlab (The MathWorks). After isolation of a cell and mapping of the receptive field with hand-held stimuli, a white noise grid was presented (Citron et al. 1981; Reid et al. 1997). The reverse correlation of spike output and stimulus was calculated to find the center of the receptive field. Spots of varying diameter centered on the receptive field were presented in a pseudorandom order to determine whether the cell showed a center-surround organization. Responses were binned into 1-ms increments, and measures of peak firing rate, initial and peak latency, maintained firing rate, and transient time constant were obtained from the mean response to the spot stimulus as described previously. Orientation selectivity was assessed by examining responses to drifting gratings with different orientations. A spatial frequency of 0.1 cycles $^{\circ}{ }^{\circ}$ and a temporal frequency of $4 \mathrm{~Hz}$ were used. This combination was found to drive virtually all cells in the sample, as $95 \%$ of LGN cells responded significantly to this combination, and spatial frequency tuning and temporal frequency tuning were not narrow for the majority of LGN cells (Van Hooser et al. 2003; see Figs. 10 and 11). We report results here for the subset of cells that exhibited significant responses.

In the cortex, 21 penetrations that were roughly perpendicular to the cortical surface were recorded as described in Heimel et al. (2005). Again, electrodes were coated with Di-I to improve histological identification. Receptive fields were mapped by hand on a tangent screen. Coarse orientation tuning curves were measured using sinusoidal gratings drifting in 12 equally spaced different directions. The stimulus comprised $16 \times 16^{\circ}$ of visual angle. Preliminary gratings had a spatial frequency of 0.2 cycles $/{ }^{\circ}$ and drifted with a temporal frequency of $4 \mathrm{~Hz}$. Stimulus conditions were pseudorandomly interleaved and shown five times. Between all stimuli presented, a gray background (luminance: $45 \mathrm{~cd} / \mathrm{m}^{2}$ ) was shown for at least $3 \mathrm{~s}$. After spatial frequency and temporal frequency preferences were mapped, a fine direction tuning curve (with 16 equally spaced directions) was measured at the optimal spatial and temporal frequency.

For all cells, azimuth $(R F x)$ and elevation $(R F y)$ were measured relative to an imaginary line that began at the animal's nose and extended rostrally, directly in front of the animal.

Histology. After the experiment, histological sections were prepared as described previously for LGN (Van Hooser et al. 2003) and cortex (Heimel et al. 2005; Van Hooser et al. 2005). In brief, a fluorescent Nissl stain (NeuroTrace) was used to identify the layers of the LGN, while traditional cresyl violet Nissl staining was used to identify the V1 layers. In LGN, histological records of the Di-I tracks were combined with information from the experiment, including electrode depth as measured by the manipulator, eye dominance, and the charted location of the electrode penetrations on the cortical surface to identify the 
laminar identity of each cell. In each case, the information in the histological sections agreed with our expectations from the mapping penetrations. In cortex, lesions ( $9 \mu \mathrm{A}, 3 \mathrm{~s}$, tip negative) were used to mark locations along each electrode penetration. We used the lesion sites to calibrate the electrode manipulator readings to laminar positions in the cortex as in Hawken et al. (1988).

Data analysis and statistics. Average firing rates (DC or F0 component) and response modulation at the drifting frequency (F1 component) were computed as described in Heimel et al. (2005). In calculating index values, the F1 component was always used in the LGN. In the cortex, the F1 component was used if the cell's F1 response was greater than the mean response (F0), otherwise the F0 values were used

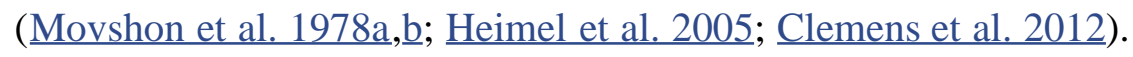

The orientation selectivity index was defined as 1 minus the circular variance (Ringach et al. 2002; Mazurek et al. 2014):

$$
1-\mathrm{CV}=\frac{\sum_{k} R\left(\theta_{k}\right) \exp \left(2 \mathrm{i} \theta_{k}\right)}{\sum_{k} R\left(\theta_{k}\right)},
$$

where $\theta_{k}$ are the direction angles used for stimulation and $R\left(\theta_{k}\right)$ is the response to angle $\theta_{k}$ (after subtraction of the spontaneous rate). Similarly, the direction selectivity index was defined but computed as 1 minus direction circular variance in direction space (Grabska-Barwinska et al. 2012; Mazurek et al. 2014):

$$
1-\operatorname{DICV}=\frac{\sum_{k} R\left(\theta_{k}\right) \exp \left(i \theta_{k}\right)}{\sum_{k} R\left(\theta_{k}\right)},
$$

To examine orientation-tuning widths, the mean responses were fit with two Gaussians following Carandini and Ferster (2000):

$$
f(O)=R_{0}+R_{p} e^{-\operatorname{Ang}(O-O p)^{2} /\left(2 \sigma^{2}\right)}+R_{n} e^{-\operatorname{Ang}(O-O p+180)^{2} /\left(2 \sigma^{2}\right)}
$$

in which $O$ is the drift direction, $R_{0}$ is the nonselectivive response, $R_{p}$ is the response to the preferred direction $O_{p}, R_{n}$ is the response to the opposite drift direction, $\sigma^{2}$ is a tuning width parameter, $\operatorname{and} \operatorname{Ang}(\theta)$ represents angular values modulo $180^{\circ}$. The mean response (F0) and modulated response (F1) were fit together and $\sigma \sqrt{\log (4)}$ was taken to be the half-width at half height (HWHH) (Van Hooser and Nelson 2006). The fitting procedure is described in full in Mazurek et al. (2014).

\section{RESULTS}

Because the gray squirrel is a relatively uncommon model system, we will first briefly outline the anatomy 
and physiology of LGN and V1 in this species.

Functional organization of LGN and V1 in the gray squirrel. In the gray squirrel, the LGN consists of five layers that receive alternating innervation from the two eyes (Kaas et al. 1972b; Fig. 1). Layers 1, 3a, and 3c receive input from the contralateral eye while layer 2 and $3 b$ receive input from the ipsilateral eye. The layers are arranged from rostromedial to caudolateral, with layer 1 being the most rostral and medial layer and layer 3c being the most caudal and lateral, bordering the optic tract.

A previous physiological study of squirrel LGN identified three functional classes of neurons, termed Xlike, Y-like, and W-like cells (Van Hooser et al. 2003). X-like cells were identified in LGN layers 1-2, while LGN layers 3abc contained Y-like and W-like cells. All layers of the gray squirrel LGN express the calcium-binding protein parvalbumin, while only layers 3abc express the calcium-binding protein calbindin (Rodman and Dieguez 2003; Felch and Van Hooser 2012), which is a marker for koniocellular/W-relay

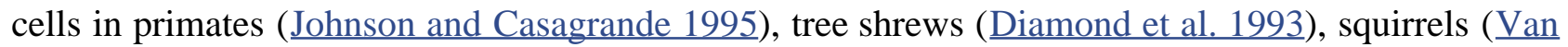
Hooser et al. 2003), and mice (Grubb and Thompson 2004). In squirrels and other mammals, koniocellular/W-cell-rich LGN layers receive projections from the superior colliculus and project to the superficial layers of visual cortex (Fitzpatrick et al. 1983; Harting and Huerta 1983; Usrey et al. 1992; Boyd and Matsubara 1996).

LGN layers 3abc in squirrel share some features of the dorsolateral shell of the mouse lateral geniculate nucleus. The dorsolateral shell in mouse LGN also has a subpopulation of calbindin-positive neurons (Grubb and Thompson 2004), receives input from the superior colliculus (Grubb and Thompson 2004), and projects to the superficial layers of cortex (Cruz-Martin et al. 2014). Previous mouse LGN studies that have employed imaging or histology have noted that this dorsolateral region of mouse LGN contains orientation- and/or direction-selective cells (Marshel et al. 2012; Piscopo et al. 2013; Cruz-Martin et al. 2014).

The gray squirrel primary visual cortex (V1) is divided into a lateral binocular zone that mediates the

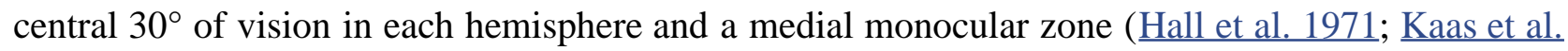
$\underline{1972 b}$ ). We recorded cells primarily in this binocular region, as it is the most highly represented space in the LGN and primary visual cortex (Kaas et al. 1972b). As in other mammals, the gray squirrel visual cortex has six layers. No cells were recorded in layer 1, but the sample was otherwise well distributed across the cortical layers (Heimel et al. 2005).

The comparison of orientation and direction selectivity across LGN and cortex provides an advantage for interpreting results in LGN. The mere act of sampling noisy neural responses means that the empirical orientation or direction selectivity that is calculated for any given cell will be greater than zero (Mazurek et al. 2014). The empirical index values calculated for the LGN provide a baseline for interpreting values that are observed in the cortex.

Orientation selectivity and direction selectivity are weak in squirrel LGN. Using sinusoidal drifting gratings, we examined the orientation and direction selectivity of 165 neurons in the LGN and 161 neurons in V1 (see Table 1). We first compared orientation selectivity values in squirrel LGN and V1 (Fig. 2). Representative tuning curves for LGN and V1 neurons are shown in Fig. $2, A$ and $B$. Orientation selectivity index values ( 1 - circular variance) in the LGN were significantly lower than those in V1 (Fig. 2C; $P<$ 0.001, Kruskal-Wallis test). Orientation selectivity was quite weak in our LGN sample; the median orientation selectivity index value was 0.11 , with a standard deviation of 0.11 . Very few neurons in the 
LGN exhibited high orientation selectivity values. LGN cells exhibited significantly broader tuning (HWHH) than V1 neurons $(P<0.01$, Kruskal-Wallis test).

At the population level, both squirrel LGN and V1 exhibited very weak direction selectivity index values ( 1 - circular variance in direction space). The median direction selectivity index value ( 1 - circular variance in direction space) for cortical neurons was 0.08 , with a standard deviation of 0.13 , while LGN neurons had a median direction selectivity index value of 0.09 , with a standard deviation of 0.10 (Fig. 2C, right). While selectivity was low overall, individual example cells did exhibit substantial tuning (as in mice).

Another way to examine the differences in orientation selectivity across LGN and V1 is to perform discriminability analysis: given a population of N LGN and N V1 neurons, how well could an observer identify which population was from LGN and which was from V1? The LGN/V1 discriminability curve (1,000 simulations for each value of $\mathrm{N}$ ) is shown in Fig. 2D. The curve indicates that the LGN and V1 populations are easily discriminated: the recorded structure can be identified with $>90 \%$ accuracy by examining just three neurons.

Laminar analysis of orientation and direction selectivity. Next, we examined orientation selectivity values across the layers of squirrel LGN and V1 (Fig. 3). Previous studies have shown that orientation selectivity does not vary significantly across the layers of cortex in squirrel ( 0.42). Here, we found that orientation selectivity values were weak and did not vary significantly across the layers of the LGN $(P=0.43)$.

Although direction selectivity index values are relatively low in V1, there are differences in direction selectivity across the cortical layers, as previously described (Heimel et al. 2005). V1 layer 6 exhibits increased direction selectivity compared with the other layers. Figure 4 shows direction selectivity across the layers of squirrel LGN and V1. We find that direction selectivity also varied across the layers of the LGN. Although selectivity values are weak overall, using a Kruskal-Wallis test (and excluding the lone cell categorized "3b or 3c"), we found that the small differences in direction selectivity across the layers in squirrel LGN were significant $(P<0.039)$ and that layers 3abc exhibit increased direction selectivity compared with layers 1 and 2.

The previous analyses showed that there were a handful of LGN cells that exhibited a strong bias for stimulus orientation or direction, but they do not allow us to distinguish the fraction of orientationselective cells that also exhibit direction selectivity. Because we have used moving gratings to assess selectivity, all direction-selective cells are by definition orientation selective. Figure 5 shows a scatter plot of orientation selectivity and direction selectivity for cells in squirrel LGN. We observed a variety of response types, including cells with high orientation selectivity but low direction selectivity and vice versa.

Retinotopic location. While orientation (and direction) selectivity index values were low overall, there remained the possibility that certain orientations or directions were overrepresented in certain portions of the visual field, such that a particular region of the visual field might exhibit significant selectivity. For example, in the mouse, vertical orientations are overrepresented in the LGN ( rabbit, direction-selective retinal ganglion cells are more common in the region that represents the superficial visual field (Swadlow and Weyand 1985). If there were regional orientation biases, and they corresponded between LGN and cortex, then it might be possible that cortex could directly inherit its orientation selectivity from biased LGN cells in that particular region and there might be no need to imagine other mechanisms for determining orientation selectivity. We therefore looked for a potential bias 
in the angle preference in orientation space for the squirrel LGN and squirrel visual cortex. Overall, angle preference was evenly distributed in orientation space for cells in both the squirrel visual cortex and squirrel LGN (Fig. 6A; both $P>0.1$, Rayleigh test for circular nonuniformity). Further, we also examined the distributions of preferred angle vs. retinotopic field position ( $R F x$ and $R F y$, azimuth and elevation, respectively) for the LGN and cortex, and we observed no evidence of anisotropy of orientation preferences and retinotopic location for the locations sampled (Fig. 6, B and $C$ ). In a separate analysis (not shown), we also determined that the measured orientation preferences in these central LGN cells did not exhibit an anisotropy with respect to the radial angle of the receptive field as measured from either the optic disk (Rayleigh test, $P=0.65$ ) or the front of the animal (Rayleigh test, $P=0.28$ ), similar to central retinal ganglion cells in the cat (Levick and Thibos 1980). The lack of a systematic relationship between orientation preferences of LGN cells and cortical cells recorded at the same receptive field location suggests that the orientation selectivity that is observed in the cortex is unlikely to be exclusively inherited from individual LGN cell response properties.

Orientation selectivity across visual processing stages. To better understand the development of visual processing from LGN to cortex and how this varies across mammals, we compared the orientation tuning curves in the neurons of the visual cortex and the neurons of the LGN for the gray squirrel and tree shrew ( Fig. 7) using a figure format that is similar to a recent comparison of these transformations in the mouse and cat ( $\underline{\text { Scholl et al. 2013 }}$, their Fig. 4). The membrane potential data are from simple and complex cells in layers 2/3 and 4 (Van Hooser et al. 2006; see their Fig. 7 for individual cell examples and their Fig. 8 for summary data). The tree shrew data were taken from a recent study (Van Hooser et al. 2013). Both squirrels and tree shrews exhibit relatively poor tuning for orientation in LGN and exhibit a large transformation in orientation selectivity from LGN to cortex. In the case of the tree shrew, the emergence of orientation selectivity does not occur in layer 4 (the primary recipient layer of LGN input) but rather in layer 2/3 (Humphrey and Norton 1980; Chisum et al. 2003). In squirrel, both subthreshold membrane potential response (see Fig. 7B, reproduced from Van Hooser et al. 2006) and spiking responses in cortex exhibit stronger orientation tuning than in LGN cells. This provides further evidence consistent with the idea that orientation selectivity in the cortex is not simply inherited from the LGN but rather requires some additional steps, such as an elongated patterning of LGN connections to cortex (Hubel and Wiesel 1963a; Reid and Alonso 1995), a threshold nonlinearity (Carandini and Ferster 2000; Finn et al. 2007; Priebe and Ferster 2012), or intracortical processing (Somers et al. 1995; Liu et al. 2011). In the tree shrew, orientation selectivity increases dramatically in layer $2 / 3$ via a process known to involve elongated patterned connections from layer 4 (Mooser et al. 2004).

\section{DISCUSSION}

In this study, we compared orientation and direction selectivity of LGN cells to that found in primary visual cortical neurons of the gray squirrel. We found that orientation selectivity index values for cells in the central visual representation of gray squirrel LGN were significantly lower than those of cells in the gray squirrel visual cortex, with no significant variation across the layers in both the LGN and the cortex. The distributions in direction selectivity values were not significantly different between cells in the LGN and visual cortex; both exhibited weak values. The small differences in direction selectivity across the layers in the squirrel LGN were significant, with layer 3abc exhibiting modestly increased direction index values. Overall, angle preference was evenly distributed in orientation space for cells in both the squirrel LGN and squirrel visual cortex, and we observed no evidence of anisotropy of orientation preferences and 
retinotopic location for the locations sampled.

Orientation selectivity in LGN: are there major differences across species? Classic studies in the cat and primate LGN identified center-surround neurons of various subtypes, such as sustained and transient, or brisk and sluggish (Hubel and Wiesel 1961; Wiesel and Hubel 1966; Cleland et al. 1971, 1975; Wilson et al. 1976). Further studies have found evidence for orientation and direction biases in both retinal ganglion cells and LGN neurons in cats (Leventhal and Schall 1983; Shou et al. 1995; Zhou et al. 1995) and primates (Lee et al. 1979; Smith et al. 1990; Xu et al. 2002; Cheong et al. 2013). Although some individual neurons in these samples exhibit remarkably strong orientation or direction selectivity (including our own sample), the average amount of selectivity observed in LGN is much less than is found in the primary visual cortex.

Four recent studies in the mouse LGN have identified orientation-selective responses (Marshel et al. 2012; Piscopo et al. 2013; Scholl et al. 2013; Zhao et al. 2013). Some of these studies only found that a small minority of cells exhibit strong orientation selectivity cells (Marshel et al. 2012; Piscopo et al. 2013), but Scholl et al. (2013) noted that the amount of orientation selectivity that was observed across the population was similar to the orientation selectivity of subthreshold inputs to mouse visual cortex. Zhao et al. (2013) noted a high percentage of orientation-biased cells and further went on to show that these orientation biases existed in the mouse retina and persisted even if primary visual cortex was inactivated, which suggests that these orientation biases are not propagated back to the LGN from the cortex.

Our squirrel data are more consistent with the idea that there is a minority of cells that exhibit some orientation or direction selectivity but that these are relatively rare; we do find a few individual cells that are highly selective for orientation, but on a population basis the orientation selectivity in LGN is much weaker than that observed in V1.

We did not find any evidence of an anisotropy in the orientation that gave the maximum response for each cell, whereas the mouse exhibits a vertical bias (Zhao et al. 2013). The fact that qualities of orientation selectivity differ between squirrel and mouse likely reflects the very different ecological niches that are inhabited by squirrels and mice: squirrels are arboreal and depend on vision for navigation and predator avoidance, while mice are nocturnal, burrowing animals. These differences can serve as a reminder that there is no "typical” rodent visual organization; instead, rodents are the most diverse mammalian order, comprising fully $40 \%$ of all mammalian species.

Diversity of retinal and LGN direction selectivity across mammals and across the visual field: should we expect all mammals to have a large LGN direction-selective channel?

The prevalence of retinal cell types varies greatly across mammals. For example, while the gray squirrel exhibits a rod to cone ratio of 40/60, the tree shrew has a ratio of 5/95, and the cat exhibits a ratio of $>95 / 5$ (Steinberg et al. 1973; Ogden 1975; West and Dowling 1975; La Vail 1976; Schneider and Zrenner 1986; Muller and Peichl 1989; Wikler et al. 1990). This variability extends to the fraction of direction-selective cells. Among rodents and lagomorphs the percentage of DSRGs is relatively high. In the gray squirrel

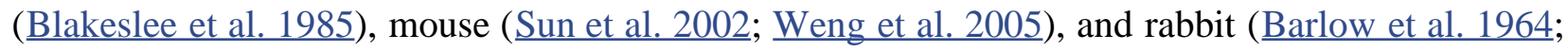
Swadlow and Weyand 1985) 10, 22, and 15-41\% of retinal ganglion cells have been classified as direction-selective, respectively. By contrast, only $1 \%$ of retinal ganglion cells in the cat have been classified as direction selective (Cleland and Levick 1974), and direction-selective cells appear to be very rare in the macaque retina, if they exist (De Monasterio and Gouras 1975).

In the rabbit and the squirrel, the distribution of DSGCs varies across the visual field. Centrally, both 
squirrels and rabbits have relatively few DSGCs (Blakeslee et al. 1985; Swadlow and Weyand 1985), but this percentage increases as one moves to the periphery. In rabbits, this has been quantified: centrally, $10 \%$ of optic tract fibers exhibit direction selectivity, while this percentage increases to $20 \%$ as one

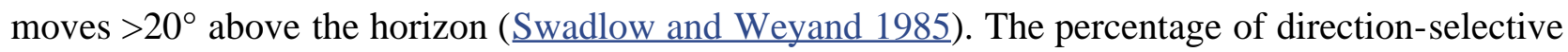
neurons in LGN is related to the values in the optic tract, except that, centrally, there are almost no direction-selective LGN cells, while the percentage increases to $20 \%$ in the periphery ( $>20^{\circ}$ above the horizon) (Swadlow and Weyand 1985). Similarly, in the mouse, Piscopo et al. (2013) found that the fraction of orientation-selective or direction-selective LGN neurons was relatively low in the central visual field and increased out towards the periphery.

These differences in abundance of orientation-selective and direction-selective cells across animals and across the visual field likely means that the contribution of a retinally derived orientation- or directionselective channels to LGN varies from species to species and across the visual field. Animals that have few direction-selective retinal ganglion cells would likely have very few direction-selective LGN cells.

There are differences in the prevalence of orientation- and direction-selective cells between LGN and cortex in the central visual field across species.

Just as the composition of retinal and LGN cells varies across mammals, so too does the orientation and direction selectivity that is found in visual cortex. Nearly all cells in cat visual cortex exhibit strong tuning for stimulus orientation (Hubel and Wiesel 1963a; Gilbert 1977), and more than two-thirds of cells exhibit substantial tuning for direction (Gilbert 1977). The intensity of this direction tuning in cat visual cortex varies across the cortical surface, according to location within the cortical direction map (Weliky et al. 1996; Ohki et al. 2005). In the monkey, cells in certain layers exhibit strong tuning for direction, but direction selectivity is not present in all cortical layers (Orban et al. 1986; Hawken et al. 1988). Mice and rabbits exhibit both abundant orientation and direction selectivity in the visual cortex, particularly in layer 4 and layer 2/3 (Niell and Stryker 2008; Rochefort et al. 2011; Hei et al. 2014), while squirrels and tree shrews show strong orientation tuning but relatively weak direction selectivity (Heimel et al. 2005; Van Hooser et al. 2005, 2013).

The prevalence of cortical orientation and direction selectivity across animals does not correlate well with the prevalence of orientation- and direction-selective cells in LGN. Cats and monkeys exhibit very few direction-selective retinal ganglion cells or LGN neurons, yet in the cat most V1 neurons are selective for both orientation and direction. In the central visual field of the rabbit, there are few direction-selective LGN neurons, yet there are abundant direction-selective cortical neurons (Hei et al. 2014). This evidence is consistent with the idea that cortical direction selectivity arises in cortical circuits in species that exhibit a high percentage of direction-selective cells in the cortex.

The lack of a clear correlation between orientation and direction selectivity in the LGN and cortex begs the question of whether orientation- and direction-selective LGN cells provide input to orientation- and direction-selective cells in cortex. A recent beautiful study using synaptic tracers has shown that directionselective LGN cells in the mouse do provide input to neurons in the superficial layers of mouse cortex (Cruz-Martin et al. 2014), so they are in a position to confer direction selectivity onto superficial cortical neurons. However, there are two lines of circumstantial evidence that make it unlikely that all or most direction selectivity in the cortex is derived from LGN. First, direction-selective V1 cells are found in central regions in mouse and rabbit, whereas there are few direction-selective LGN cells in this region (Swadlow and Weyand 1985; Piscopo et al. 2013). Second, in both the mouse and the rabbit, directionselective LGN cells do not respond in a linear manner to grating stimulation, yet the direction-selective 
cortical neurons in layer 4 are quite linear (simple cells) (Niell and Stryker 2008; Piscopo et al. 2013; $\underline{\text { Hei }}$ et al. 2014).

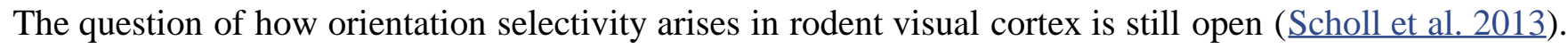
In cats and tree shrews, orientation-selective cortical neurons receive inputs from unselective cells that have colinear receptive fields; in the cat, these unoriented cells are in the LGN, and in tree shrew they are in layer 4 (Reid and Alonso 1995; Mooser et al. 2004). Orientation selectivity in the central representation of gray squirrel LGN is quite weak, and orientation selectivity in V1 is much stronger, suggesting that orientation biases in individual LGN neurons do not contribute strongly to cortical orientation selectivity in

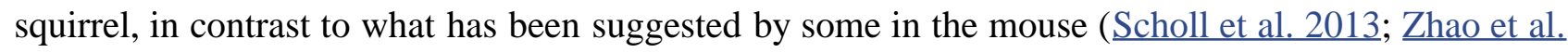
2013). It remains unclear whether the additional processing that is required in squirrel involves colinear feed-forward input from LGN cells ( sharpening of biases within the cortex (Ben-Yishai et al. 1995; Somers et al. 1995; Liu et al. 2009, 2011), or a combination of these mechanisms.

Support for orientation and direction selectivity and the koniocellular/W-cell pathway. In the marmoset, orientation-selective neurons have been found in the koniocellular layers of the LGN, which project to superficial cortex. In the mouse, orientation- and direction-selective neurons are concentrated in the "outer shell” of the LGN, adjacent to the optic tract (Huberman et al. 2009; Marshel et al. 2012; Piscopo et al. 2013; Cruz-Martin et al. 2014). In squirrel, we found slightly increased direction selectivity in layers 3abc. Previous studies have shown that these layers contain W cells (Van Hooser et al. 2003) that express calbindin (Felch and Van Hooser 2012), which is a marker for the koniocellular pathway in some species (Diamond et al. 1993), and project to the superficial layers (Harting and Huerta 1983). This evidence is consistent with the idea that the direction-biased neurons that are present in squirrel LGN are members of the koniocellular/W-cell class.

Conclusion. Among mammals as a whole, there is clear evidence of orientation- and direction-selective channels from retina to LGN to cortex, but the size of this pathway likely varies from species to species, even among rodents. In all mammals, there is evidence linking these cells to the koniocellular/W-cell pathway (Cheong et al. 2013; Cruz-Martin et al. 2014; but see Xu et al. 2002). Mice seem to exhibit a higher fraction of these orientation-selective and direction-selective LGN cells than other species, although the number of neurons that implement these channels in all mammals may increase in the periphery, as it does in rabbit and mouse. In central vision in monkeys, cats, squirrels, and tree shrews, the fraction of orientation- and direction-biased cells in LGN appears to be relatively small.

\section{GRANTS}

This work was funded by the National Science Foundation Grant IOS 1120938 and National Eye Institute Grant EY-022122 (both to S. D. Van Hooser).

\section{DISCLOSURES}

No conflicts of interest, financial or otherwise, are declared by the author(s). 
Author contributions: J.B.Z. and S.D.V.H. analyzed data; J.B.Z. and S.D.V.H. interpreted results of experiments; J.B.Z. prepared figures; J.B.Z. drafted manuscript; J.B.Z., J.A.H., and S.D.V.H. edited and revised manuscript; J.B.Z., J.A.H., and S.D.V.H. approved final version of manuscript; J.A.H. and S.D.V.H. conception and design of research; J.A.H. and S.D.V.H. performed experiments.

\section{ACKNOWLEDGMENTS}

We thank Sacha Nelson, in whose laboratory the recordings were made.

\section{REFERENCES}

Barlow HB, Hill RM, Levick WR Retinal ganglion cells responding selectively to direction and speed of image motion in the rabbit. J Physiol 173: 377-407, 1964. [PMCID: PMC1368915]

[PubMed: 14220259]

Ben-Yishai R, Bar-Or RL, Sompolinsky H Theory of orientation tuning in visual cortex. Proc Natl Acad Sci USA 92: 3844-3848, 1995. [PMCID: PMC42058] [PubMed: 7731993]

Blakeslee B, Jacobs GH, McCourt ME Anisotropy in the preferred directions and visual field location of directionally-selective optic nerve fibers in the gray squirrel. Vision Res 25: 615-618, 1985.

[PubMed: 4060616]

Blakeslee B, Jacobs GH, Neitz J Spectral mechanisms in the tree squirrel retina. J Comp Physiol A 162: 773-780, 1988. [PubMed: 3397920]

Boyd JD, Matsubara JA Laminar and columnar patterns of geniculocortical projections in the cat: relationship to cytochrome oxidase. J Comp Neurol 365: 659-682, 1996. [PubMed: 8742309]

Brainard DH. The Psychophysics Toolbox. Spatial Vis 10: 433-436, 1997.

Carandini M, Ferster D Membrane potential and firing rate in cat primary visual cortex. J Neurosci 20: 470-484, 2000. [PubMed: 10627623]

Casagrande VA, Norton TT Lateral geniculate nucleus: a review of its physiology and function. In: The Neural Basis of Visual Function, edited by Leventhal AG, editor. Basingstoke, UK: Macmillan, 1991, p. 41-84.

Cheong SK, Tailby C, Solomon SG, Martin PR Cortical-like receptive fields in the lateral geniculate nucleus of marmoset monkeys. J Neurosci 33: 6864-6876, 2013. [PubMed: 23595745]

Chisum HJ, Mooser F, Fitzpatrick D Emergent properties of layer 2/3 neurons reflect the collinear arrangement of horizontal connections in tree shrew visual cortex. J Neurosci 23: 2947-2960, 2003. [PubMed: 12684482]

Citron MC, Kroeker JP, McCann GD Nonlinear interactions in ganglion cell receptive fields. J Neurophysiol 46: 1161-1176, 1981. [PubMed: 6275040]

Cleland BG, Levick WR Properties of rarely encountered types of ganglion cells in the cat's retina and an overall classification. J Physiol 240: 457-492, 1974. [PMCID: PMC1331024]

[PubMed: 4420300]

Cleland BG, Dubin MW, Levick WR Sustained and transient neurones in the cat's retina and lateral geniculate nucleus. J Physiol 217: 473-496, 1971. [PMCID: PMC1331787] [PubMed: 5097609]

Cleland BG, Levick WR, Wassle H Physiological identification of a morphological class of cat retinal ganglion cells. J Physiol 248: 151-171, 1975. [PMCID: PMC1309512] [PubMed: 1151804]

Clemens JM, Ritter NJ, Roy A, Miller JM, Van Hooser SD The laminar development of direction selectivity in ferret visual cortex. J Neurosci 32: 18177-18185, 2012. [PMCID: PMC3532899] 
[PubMed: 23238731]

Cruz-Martin A, El-Danaf RN, Osakada F, Sriram B, Dhande OS, Nguyen PL, Callaway EM, Ghosh A, Huberman AD A dedicated circuit links direction-selective retinal ganglion cells to the primary visual cortex. Nature 507: 358-361, 2014. [PMCID: PMC4143386] [PubMed: 24572358]

De Monasterio FM, Gouras P Functional properties of ganglion cells of the rhesus monkey retina. J Physiol 251: 167-195, 1975. [PMCID: PMC1348381] [PubMed: 810576]

De Valois RL, Yund EW, Hepler N The orientation and direction selectivity of cells in macaque visual cortex. Vision Res 22: 531-544, 1982. [PubMed: 7112953]

Diamond IT, Fitzpatrick D, Schmechel D Calcium binding proteins distinguish large and small cells of the ventral posterior and lateral geniculate nuclei of the prosimian galago and the tree shrew (Tupaia belangeri). Proc Natl Acad Sci USA 90: 1425-1429, 1993. [PMCID: PMC45886]

[PubMed: 8434002]

DiCarlo JJ, Lane JW, Hsiao SS, Johnson KO Marking microelectrode penetrations with fluorescent dyes. J Neurosci Methods 64: 75-81, 1996. [PubMed: 8869487]

Felch DL, Van Hooser SD Molecular compartmentalization of lateral geniculate nucleus in the gray squirrel (Sciurus carolinensis). Front Neuroanat 6: 12, 2012. [PMCID: PMC3322329] [PubMed: 22514523]

Finn IM, Priebe NJ, Ferster D The emergence of contrast-invariant orientation tuning in simple cells of cat visual cortex. Neuron 54: 137-152, 2007. [PMCID: PMC1993919] [PubMed: 17408583]

Fitzpatrick D, Itoh K, Diamond IT The laminar organization of the lateral geniculate body and the striate cortex in the squirrel monkey (Saimiri sciureus). J Neurosci 3: 673-702, 1983. [PubMed: 6187901]

Gilbert CD. Laminar differences in receptive field properties of cells in cat primary visual cortex. $\mathrm{J}$ Physiol 268: 391-421, 1977. [PMCID: PMC1283670] [PubMed: 874916]

Girman SV, Sauve Y, Lund RD Receptive field properties of single neurons in rat primary visual cortex. J Neurophysiol 82: 301-311, 1999. [PubMed: 10400959]

Grabska-Barwinska A, Ng BS, Jancke D Orientation selective or not? Measuring significance of tuning to a circular parameter. J Neurosci Methods 203: 1-9, 2012. [PubMed: 21924292]

Grubb MS, Thompson ID Biochemical and anatomical subdivision of the dorsal lateral geniculate nucleus in normal mice and in mice lacking the beta2 subunit of the nicotinic acetylcholine receptor. Vision Res 44: 3365-3376, 2004. [PubMed: 15536004]

Hall WC, Kaas JH, Killackey H, Diamond IT Cortical visual areas in the grey squirrel (Sciurus carolinesis): a correlation between cortical evoked potential maps and architectonic subdivisions. J Neurophysiol 34: 437-452, 1971. [PubMed: 5560040]

Harting JK, Huerta MF The geniculostriate projection in the grey squirrel: preliminary autoradiographic data. Brain Res 272: 341-349, 1983. [PubMed: 6616208]

Hawken MJ, Parker AJ Contrast sensitivity and orientation selectivity in lamina IV of the striate cortex of Old World monkeys. Exp Brain Res 54: 367-372, 1984. [PubMed: 6723856]

Hawken MJ, Parker AJ, Lund JS Laminar organization and contrast sensitivity of direction-selective cells in the striate cortex of the Old World monkey. J Neurosci 8: 3541-3548, 1988.

[PubMed: 3193169]

Hei X, Stoelzel CR, Zhuang J, Bereshpolova Y, Huff JM, Alonso JM, Swadlow HA Directional selective neurons in the awake LGN: response properties and modulation by brain state. $\mathrm{J}$ Neurophysiol 112: 362-373, 2014. [PMCID: PMC4064408] [PubMed: 24790175]

Heimel JA, Van Hooser SD, Nelson SB Laminar organization of response properties in primary visual 
cortex of the gray squirrel (Sciurus carolinensis). J Neurophysiol 94: 3538-3554, 2005.

[PubMed: 16000528]

Hubel DH, Wiesel TN Receptive fields of single neurones in the cat's striate cortex. J Physiol 148: 574591, 1959. [PMCID: PMC1363130] [PubMed: 14403679]

Hubel DH, Wiesel TN Integrative action in the cat's lateral geniculate body. J Physiol 155: 385-398,

1961. [PMCID: PMC1359861] [PubMed: 13716436]

Hubel DH, Wiesel TN Shape and arrangement of columns in cat's striate cortex. J Physiol 165: 559568, 1963a. [PMCID: PMC1359325] [PubMed: 13955384]

Hubel DH, Wiesel TN Receptive fields of cells in striate cortex of very young, visually inexperienced kittens. J Neurophysiol 26: 994-1002, 1963b. [PubMed: 14084171]

Hubel DH, Wiesel TN Receptive fields and functional architecture of monkey striate cortex. J Physiol 195: 215-243, 1968. [PMCID: PMC1557912] [PubMed: 4966457]

Huberman AD, Wei W, Elstrott J, Stafford BK, Feller MB, Barres BA Genetic identification of an OnOff direction-selective retinal ganglion cell subtype reveals a layer-specific subcortical map of posterior motion. Neuron 62: 327-334, 2009. [PMCID: PMC3140054] [PubMed: 19447089]

Humphrey AL, Norton TT Topographic organization of the orientation column system in the striate cortex of the tree shrew (Tupaia glis). I. Microelectrode recording. J Comp Neurol 192: 531-547, 1980. [PubMed: 7419743]

Ibbotson MR, Mark RF Orientation, and spatiotemporal tuning of cells in the primary visual cortex of an Australian marsupial, the wallaby Macropus eugenii. J Comp Physiol A Neuroethol Sens Neural Behav Physiol 189: 115-123, 2003. [PubMed: 12607040]

Jacobs GH, Birch DG, Blakeslee B Visual acuity and spatial contrast sensitivity in tree squirrels. Behav Proc 7: 367-375, 1982.

Johnson JK, Casagrande VA Distribution of calcium-binding proteins within the parallel visual pathways of a primate (Galago crassicaudatus). J Comp Neurol 356: 238-260, 1995.

[PubMed: 7629317]

Kaas JH, Hall WC, Diamond IT Visual cortex of the grey squirrel (Sciurus carolinensis): architectonic subdivisions and connections from the visual thalamus. J Comp Neurol 145: 273-305, 1972 .

[PubMed: 5030907]

Kaas JH, Guillery RW, Allman JM Some principles of organization in the dorsal lateral geniculate nucleus. Brain Behav Evol 6: 253-299, 1972b. [PubMed: 4196831]

Kuffler SW. Discharge patterns and functional organization of mammalian retina. J Neurophysiol 16: 37-68, 1953. [PubMed: 13035466]

La Vail MM. Survival of some photoreceptor cells in albino rats following long-term exposure to continuous light. Invest Ophthalmol 15: 64-70, 1976. [PubMed: 1245384]

Lee BB, Creutzfeldt OD, Elepfandt A The responses of magno- and parvocellular cells of the monkey's lateral geniculate body to moving stimuli. Exp Brain Res 35: 547-557, 1979. [PubMed: 110614]

Leventhal AG, Schall JD Structural basis of orientation sensitivity of cat retinal ganglion cells. J Comp Neurol 220: 465-475, 1983. [PubMed: 6643739]

Leventhal AG, Thompson KG, Liu D, Zhou Y, Ault SJ Concomitant sensitivity to orientation, direction, and color of cells in layers 2, 3, and 4 of monkey striate cortex. J Neurosci 15: 1808-1818, 1995.

[PubMed: 7891136]

Levick WR, Thibos LN Orientation bias of cat retinal ganglion cells. Nature 286: 389-390, 1980.

[PubMed: 7402319]

Lien AD, Scanziani M Tuned thalamic excitation is amplified by visual cortical circuits. Nat Neurosci 
16: 1315-1323, 2013. [PMCID: PMC3774518] [PubMed: 23933748]

Liu BH, Li P, Sun YJ, Li YT, Zhang LI, Tao HW Intervening inhibition underlies simple-cell receptive field structure in visual cortex. Nat Neurosci 13: 89-96, 2010. [PMCID: PMC2818750] [PubMed: 19946318]

Liu BH, Li YT, Ma WP, Pan CJ, Zhang LI, Tao HW Broad inhibition sharpens orientation selectivity by expanding input dynamic range in mouse simple cells. Neuron 71: 542-554, 2011.

[PMCID: PMC3154747] [PubMed: 21835349]

Liu BH, Li P, Li YT, Sun YJ, Yanagawa Y, Obata K, Zhang LI, Tao HW Visual receptive field structure of cortical inhibitory neurons revealed by two-photon imaging guided recording. J Neurosci 29: 10520-10532, 2009. [PMCID: PMC2779138] [PubMed: 19710305]

Marshel JH, Kaye AP, Nauhaus I, Callaway EM Anterior-posterior direction opponency in the superficial mouse lateral geniculate nucleus. Neuron 76: 713-720, 2012. [PMCID: PMC3517882] [PubMed: 23177957]

Mazurek M, Kager M, Van Hooser SD Robust quantification of orientation selectivity and direction selectivity. Front Neural Circuits 8: 92, 2014. [PMCID: PMC4123790] [PubMed: 25147504]

Michael CR. Visual receptive fields of single neurons in superior colliculus of the ground squirrel. J Neurophysiol 35: 815-832, 1972. [PubMed: 4569705]

Mooser F, Bosking WH, Fitzpatrick D A morphological basis for orientation tuning in primary visual cortex. Nat Neurosci 7: 872-879, 2004. [PubMed: 15258585]

Movshon JA, Thompson ID, Tolhurst DJ Spatial summation in the receptive fields of simple cells in the cat's striate cortex. J Physiol 283: 53-77, 1978a. [PMCID: PMC1282765] [PubMed: 722589]

Movshon JA, Thompson ID, Tolhurst DJ Receptive field organization of complex cells in the cat's striate cortex. J Physiol 283: 79-99, 1978b. [PMCID: PMC1282766] [PubMed: 722592]

Muller B, Peichl L Topography of cones and rods in the tree shrew retina. J Comp Neurol 282: 581594, 1989. [PubMed: 2723153]

Niell CM, Stryker MP Highly selective receptive fields in mouse visual cortex. J Neurosci 28: 7520 7536, 2008. [PMCID: PMC3040721] [PubMed: 18650330]

Ogden TE. The receptor mosaic of Aotes trivirgatus: distribution of rods, and cones. J Comp Neurol 163: 193-202, 1975. [PubMed: 809489]

Ohki K, Chung S, Ch'ng YH, Kara P, Reid RC Functional imaging with cellular resolution reveals precise micro-architecture in visual cortex. Nature 433: 597-603, 2005. [PubMed: 15660108]

Orban GA, Kennedy H, Bullier J Velocity sensitivity and direction selectivity of neurons in areas V1 and V2 of the monkey: influence of eccentricity. J Neurophysiol 56: 462-480, 1986.

[PubMed: 3760931]

Paolini M, Sereno MI Direction selectivity in the middle lateral and lateral (ML and L) visual areas in the California ground squirrel. Cereb Cortex 8: 362-371, 1998. [PubMed: 9651131]

Pelli DG. The VideoToolbox software for visual psychophysics: transforming numbers into movies. Spat Vis 10: 437-442, 1997. [PubMed: 9176953]

Piscopo DM, El-Danaf RN, Huberman AD, Niell CM Diverse visual features encoded in mouse lateral geniculate nucleus. J Neurosci 33: 4642-4656, 2013. [PMCID: PMC3665609] [PubMed: 23486939]

Priebe NJ, Ferster D Mechanisms of neuronal computation in mammalian visual cortex. Neuron 75: 194208, 2012. [PMCID: PMC3477598] [PubMed: 22841306]

Reid RC, Alonso JM Specificity of monosynaptic connections from thalamus to visual cortex. Nature 378: 281-284, 1995. [PubMed: 7477347] 
Reid RC, Victor JD, Shapley RM The use of m-sequences in the analysis of visual neurons: linear receptive field properties. Vis Neurosci 14: 1015-1027, 1997. [PubMed: 9447685]

Ringach DL, Shapley RM, Hawken MJ Orientation selectivity in macaque V1: diversity, and laminar dependence. J Neurosci 22: 5639-5651, 2002. [PubMed: 12097515]

Robson JA, Hall WC Projections from the superior colliculus to the dorsal lateral geniculate nucleus of the grey squirrel (Sciurus carolinensis). Brain Res 113: 379-385, 1976. [PubMed: 953742]

Rochefort NL, Narushima M, Grienberger C, Marandi N, Hill DN, Konnerth A Development of direction selectivity in mouse cortical neurons. Neuron 71: 425-432, 2011. [PubMed: 21835340]

Rodman HR, Dieguez D The koniocellular pathway and the thalamo-cortical projection in the ground squirrel. In: 2003 Neuroscience Meeting Planner. New Orleans, LA: Society for Neuroscience, 2003, program 701.8 .

Schneider T, Zrenner E The influence of phosphodiesterase inhibitors on ERG and optic nerve response of the cat. Invest Ophthalmol Vis Sci 27: 1395-1403, 1986. [PubMed: 3744729]

Scholl B, Tan AY, Corey J, Priebe NJ Emergence of orientation selectivity in the mammalian visual pathway. J Neurosci 33: 10616-10624, 2013. [PMCID: PMC3693051] [PubMed: 23804085]

Semm P. Antidromically activated direction selective ganglion cells of the rabbit. Neurosci Lett 9: 207211, 1978. [PubMed: 19605219]

Shou T, Leventhal AG, Thompson KG, Zhou Y Direction biases of X and Y type retinal ganglion cells in the cat. J Neurophysiol 73: 1414-1421, 1995. [PubMed: 7643156]

Smith EL, Chino YM 3rd, Ridder WH, Kitagawa K 3rd, Langston A Orientation bias of neurons in the lateral geniculate nucleus of macaque monkeys. Vis Neurosci 5: 525-545, 1990. [PubMed: 2085469]

Snodderly DM, Gur M Organization of striate cortex of alert, trained monkeys (Macaca fascicularis): ongoing activity, stimulus selectivity and widths of receptive field activating regions. J Neurophysiol 74: 2100-2125, 1995. [PubMed: 8592200]

Somers DC, Nelson SB, Sur M An emergent model of orientation selectivity in cat visual cortical simple cells. J Neurosci 15: 5448-5465, 1995. [PubMed: 7643194]

Steinberg RH, Reid M, Lacy PL The distribution of rods and cones in the retina of the cat (Felis domesticus). J Comp Neurol 148: 229-248, 1973. [PubMed: 4700509]

Stewart DL, Chow KL, Masland RH Receptive-field characteristics of lateral geniculate neurons in the rabbit. J Neurophysiol 34: 139-147, 1971. [PubMed: 5540575]

Sun W, Li N, He S Large-scale morphological survey of mouse retinal ganglion cells. J Comp Neurol 451: 115-126, 2002. [PubMed: 12209831]

Swadlow HA, Weyand TG Receptive-field and axonal properties of neurons in the dorsal lateral geniculate nucleus of awake unparalyzed rabbits. J Neurophysiol 54: 168-183, 1985. [PubMed: 2993538]

Usrey WM, Muly EC, Fitzpatrick D Lateral geniculate projections to the superficial layers of visual cortex in the tree shrew. J Comp Neurol 319: 159-171, 1992. [PubMed: 1375607]

Van Hooser SD, Nelson SB The squirrel as a rodent model of the human visual system. Vis Neurosci 23: 765-778, 2006. [PubMed: 17020632]

Van Hooser SD, Heimel JA, Nelson SB Receptive field properties and laminar organization of lateral geniculate nucleus in the gray squirrel (Sciurus carolinensis). J Neurophysiol 90: 3398-3418, 2003. [PubMed: 12840084]

Van Hooser SD, Heimel JA, Chung S, Nelson SB Lack of patchy horizontal connectivity in primary visual cortex of a mammal without orientation maps. J Neurosci 26: 7680-7692, 2006.

[PubMed: 16855096] 
Van Hooser SD, Heimel JA, Chung S, Nelson SB, Toth LJ Orientation selectivity without orientation maps in visual cortex of a highly visual mammal. J Neurosci 25: 19-28, 2005. [PubMed: 15634763]

Van Hooser SD, Roy A, Rhodes HJ, Culp JH, Fitzpatrick D Transformation of receptive field properties from lateral geniculate nucleus to superficial V1 in the tree shrew. J Neurosci 33: 11494-11505, 2013. [PMCID: PMC3724553] [PubMed: 23843520]

Weliky M, Bosking WH, Fitzpatrick DA systematic map of direction preference in primary visual cortex. Nature 379: 725-728, 1996. [PubMed: 8602218]

Weng S, Sun W, He S Indentification of ON-OFF direction-selective ganglion cells in the mouse retina. J Physiol 562: 915-923, 2005. [PMCID: PMC1665532] [PubMed: 15564281]

West RW, Dowling JE Anatomical evidence for cone and rod-like receptors in the gray squirrel, ground squirrel, and prairie dog retinas. J Comp Neurol 159: 439-460, 1975. [PubMed: 1127139]

Wiesel TN, Hubel DH Spatial and chromatic interactions in the lateral geniculate body of the rhesus monkey. J Neurophysiol 29: 1115-1156, 1966. [PubMed: 4961644]

Wikler KC, Williams RW, Rakic P Photoreceptor mosaic: number and distribution of rods and cones in the rhesus monkey retina. J Comp Neurol 297: 499-508, 1990. [PubMed: 2384610]

Wilson PD, Rowe MH, Stone J Properties of relay cells in cat's lateral geniculate nucleus: a comparison of W-cells with X- and Y-cells. J Neurophysiol 39: 1193-1209, 1976. [PubMed: 993827]

$\mathrm{Xu}$ X, Ichida J, Shostak Y, Bonds AB, Casagrande VA Are primate lateral geniculate nucleus (LGN) cells really sensitive to orientation or direction? Vis Neurosci 19: 97-108, 2002.

[PubMed: 12180863]

Zhao X, Chen H, Liu X, Cang J Orientation-selective responses in the mouse lateral geniculate nucleus. J Neurosci 33: 12751-12763, 2013. [PMCID: PMC3728687] [PubMed: 23904611]

Zhou Y, Leventhal AG, Thompson KG Visual deprivation does not affect the orientation and direction sensitivity of relay cells in the lateral geniculate nucleus of the cat. J Neurosci 15: 689-698, 1995. [PubMed: 7823172]

\section{Figures and Tables}

Fig. 1. 


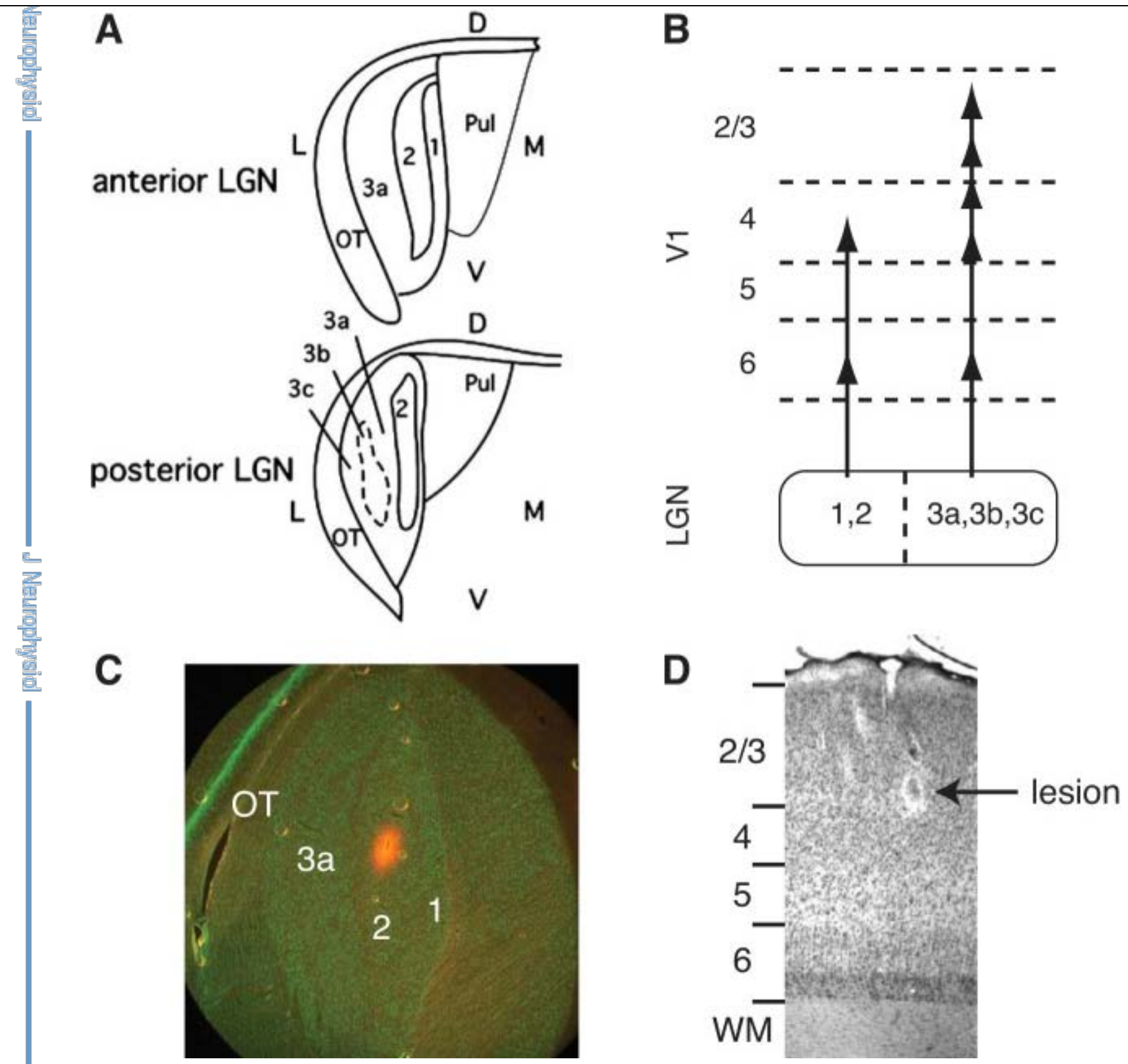

Laminar organization of squirrel lateral geniculate nucleus (LGN) and its projections to the visual cortex (V1). A: drawings of coronal sections in anterior (top) and posterior (bottom) LGN. The layers are labeled from rostromedial (1) to caudolateral (3c). Adapted from Robson and Hall (1976) with permission. Pul, pulvinar; OT, optic tract; M, medial; L, lateral; V, ventral; D, dorsal. B: major projections from LGN layers to V1 layers. LGN layers 1-2 project strongly to the center of V1 layer 4 as well as to V1 layer 6. LGN layers 3abc project strongly to the inferior and superficial boundaries of V1 layer 4, as well as to V1 layers 2/3 and 6 (Harting and Huerta 1983). C: anterior section of LGN stained with fluorescent Nissl. The electrode track (Di-I, red) is in layer 2 (an ipsilateral layer). D: Nissl stain of squirrel V1 with lesion from electrode track.

\section{Table 1.}

Summary of the laminar distribution of recorded cells from LGN and V1

\begin{tabular}{cl}
\hline Area & Animals/Cells \\
\hline LGN & 16 animals
\end{tabular}




\begin{tabular}{lll}
\hline & Layer 1 & 45 cells \\
Layer 2 & 40 cells \\
Layer 3a & 45 cells \\
Layer 3b & 16 cells \\
Layer 3b/c & 1 cell \\
Layer 3c & 18 cells \\
Undetermined & 2 cells \\
V1 & 16 animals \\
Layer 2/3 & 37 cells \\
Layer 4 & 28 cells \\
Layer 5 & 20 cells \\
Layer 6 & 19 cells \\
Undetermined & 57 cells \\
\hline
\end{tabular}

LGN, lateral geniculate nucleus; V1, visual cortex.

Fig. 2.

A

$20 \%$

LGN

B
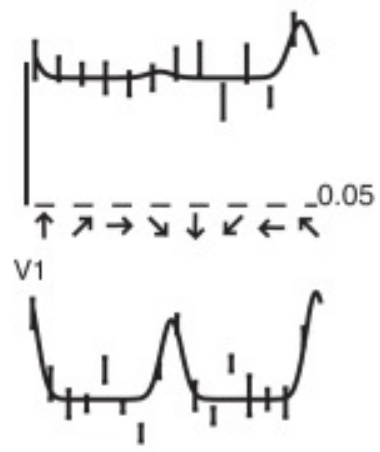

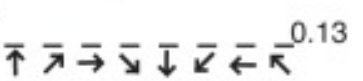

C

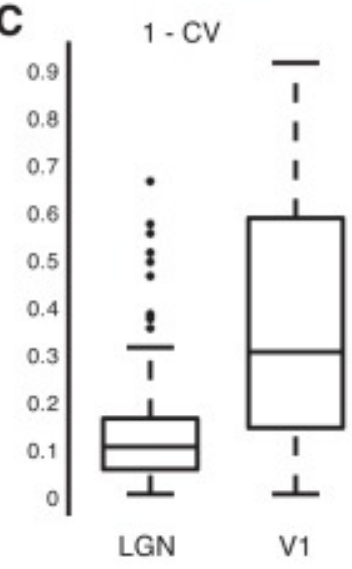

$40 \%$
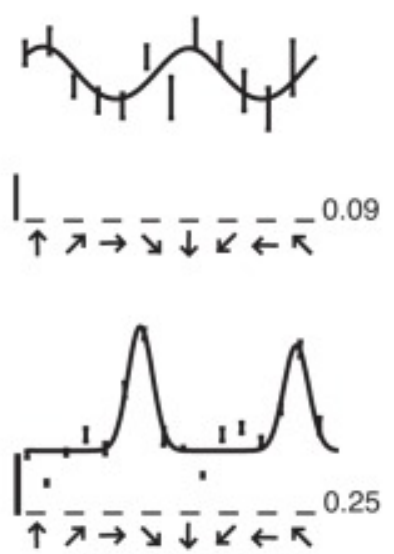
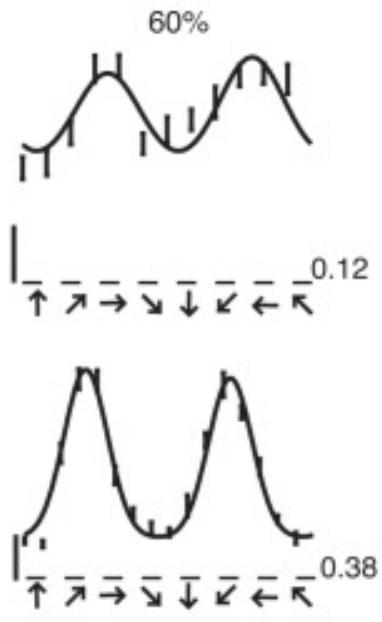

$80 \%$
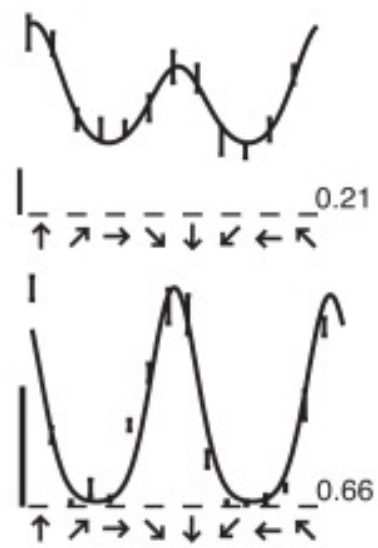
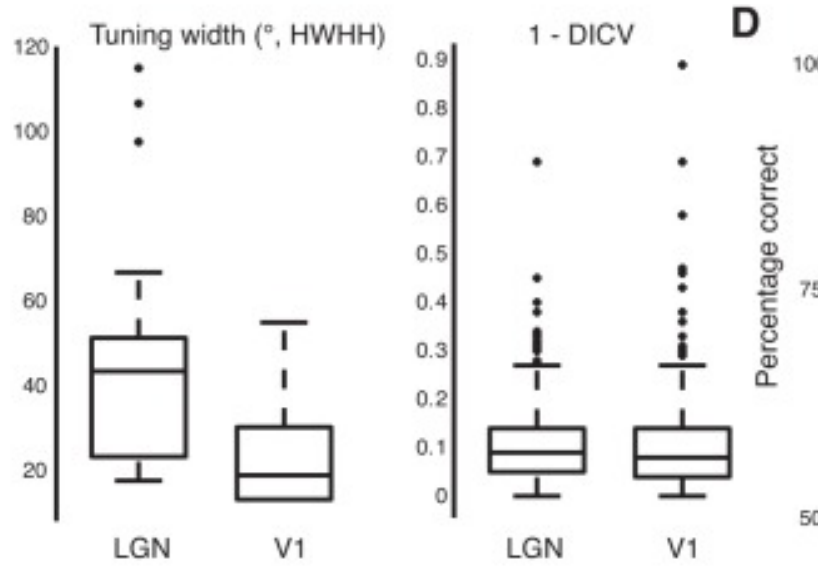

Discriminability Analysis

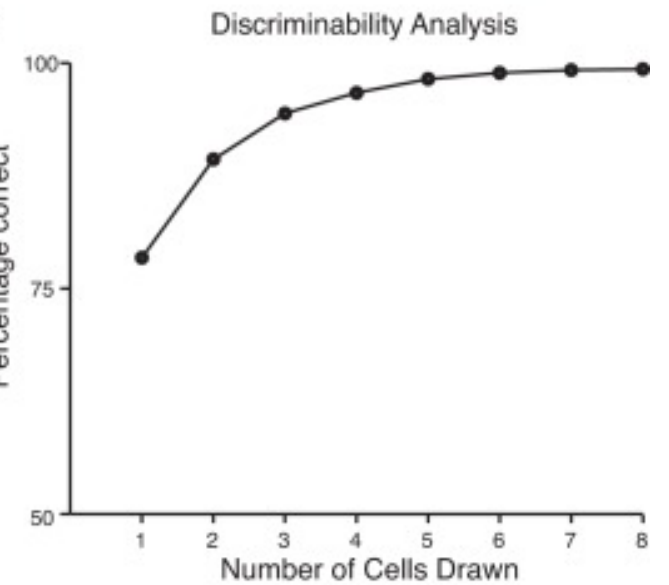

Comparisons of orientation selectivity in squirrel LGN and V1. A: individual examples of orientation/direction tuning curves. The curves shown are close to the 20th, 40th, 60th, and 80th percentile values for orientation selectivity that we 
observed in the study. B: Same, for V1. C: box plot of orientation selectivity and direction selectivity. Cells in the squirrel visual cortex exhibited a wider range of orientation selectivity values than cells in LGN, the average orientation index values were higher $(P<0.001$, Kruskal-Wallis test), and orientation tuning width among cells with some tuning (ANOVA $P<0.05$ ) was higher in cortex. Direction selectivity ranges were similar for the visual cortex and LGN; both exhibited weak direction selectivity $(P=0.32)$. $D$ : discriminability of LGN and V1 by orientation: or how well could one distinguish the LGN from V1 if one examined $N$ cells from each group, unlabeled? Even with a single cell, one would be able to distinguish LGN from V1 with over $80 \%$ accuracy, indicating that the populations are quite distinct in terms of orientation selectivity index.

Fig. 3. 


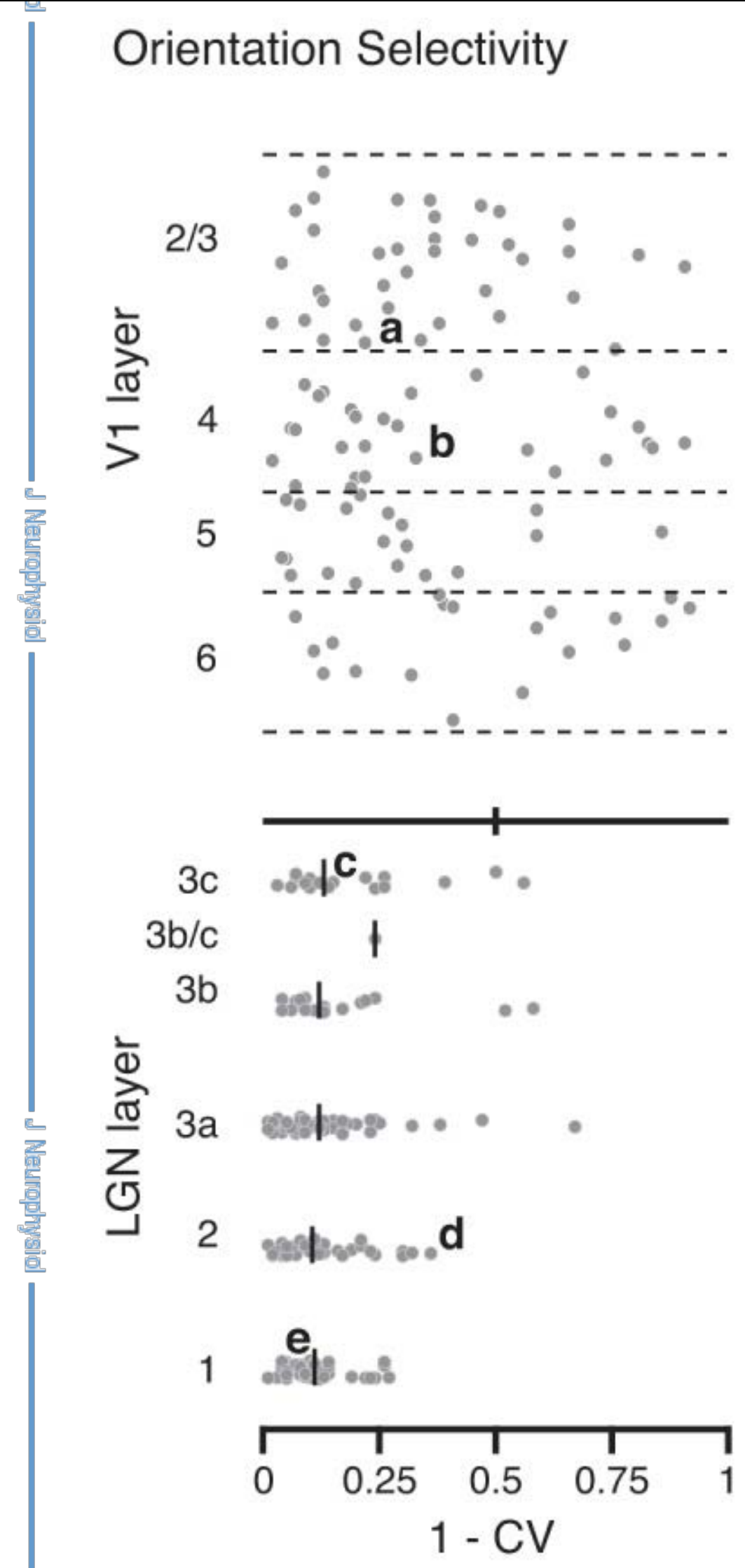

a

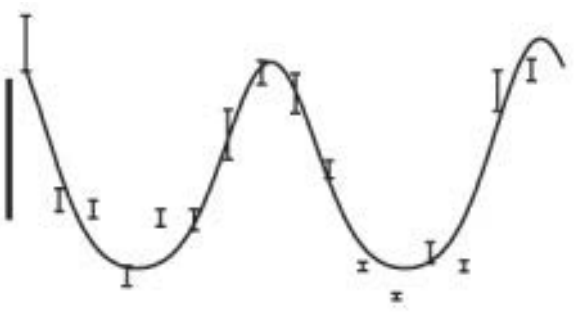

b

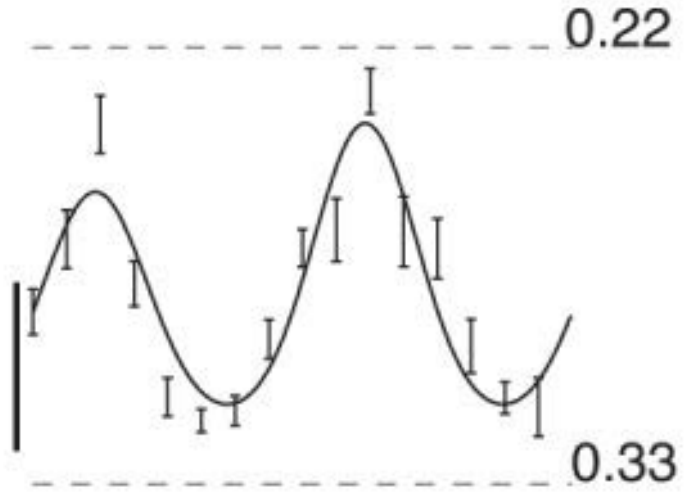

C

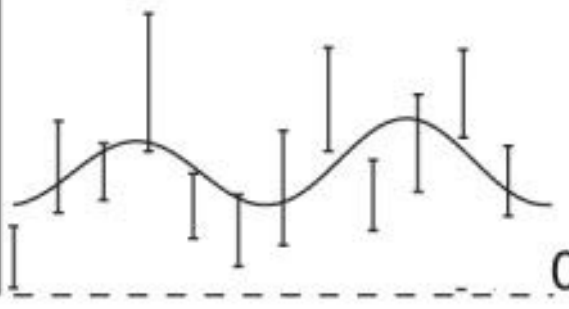

0.15

d
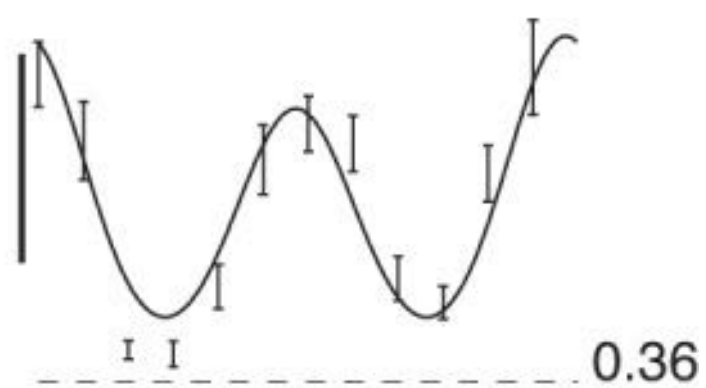

e

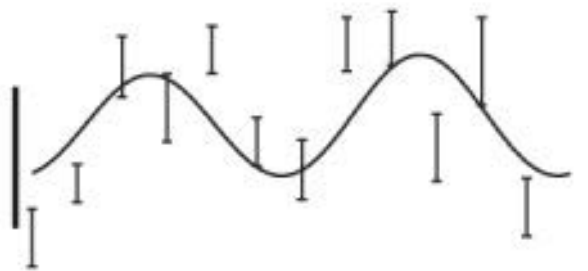

Laminar profile of orientation selectivity in squirrel LGN and V1. Neurons from squirrel visual cortex exhibited a wide range of orientation selectivity index values, while LGN cells exhibited weak orientation selectivity. Left: laminar profile of the 1 - circular variance $(1-\mathrm{CV})$ for the cortex as a function of depth and for the LGN as a function of layer. Right: example tuning curves of neurons $(a-e)$. In the LGN, very few neurons exhibited high orientation selectivity index 
Fig. 4.

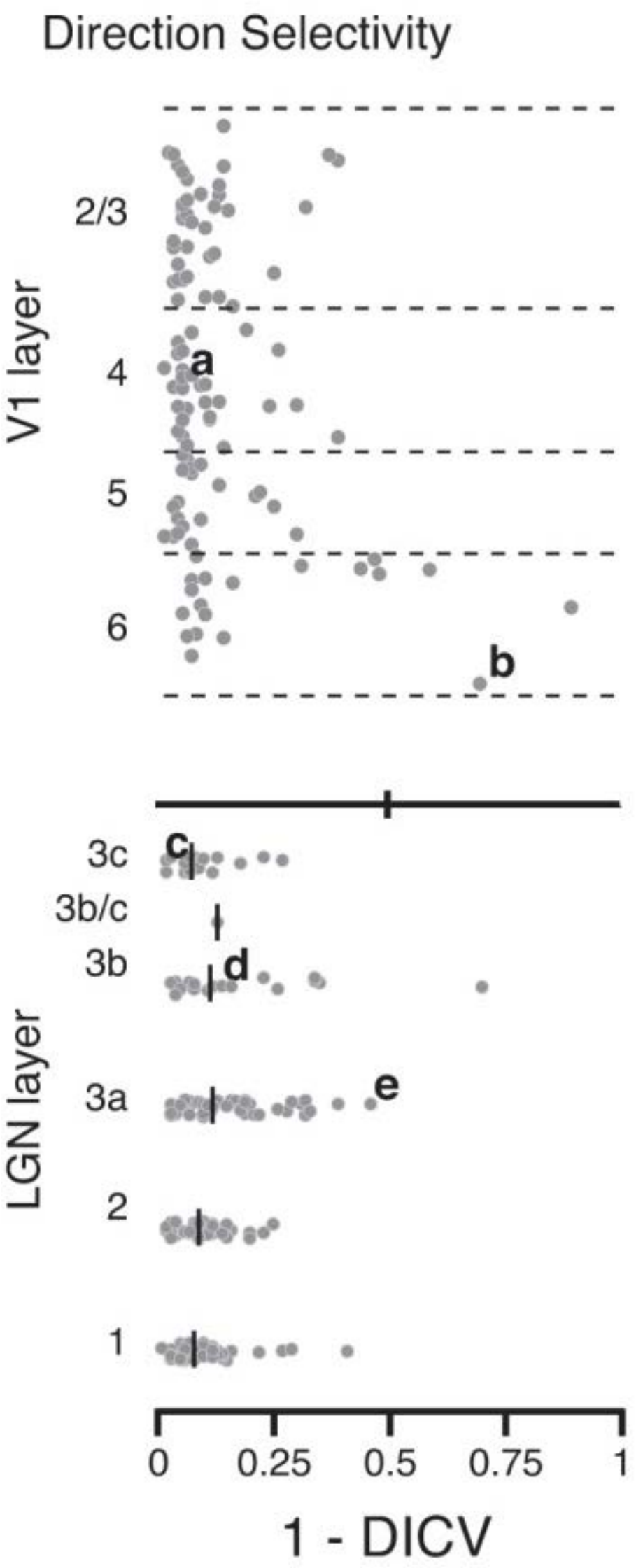

a

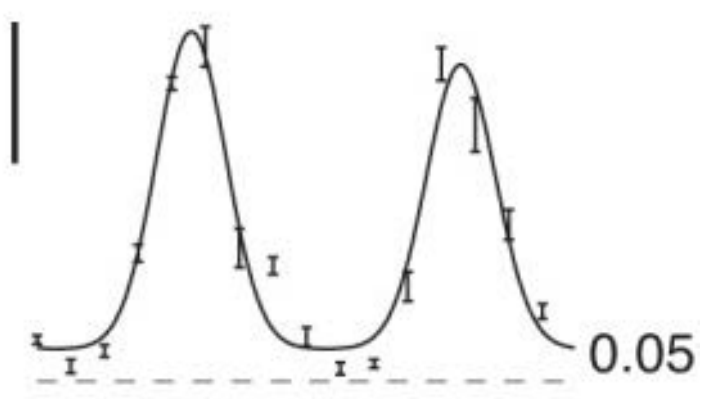

b

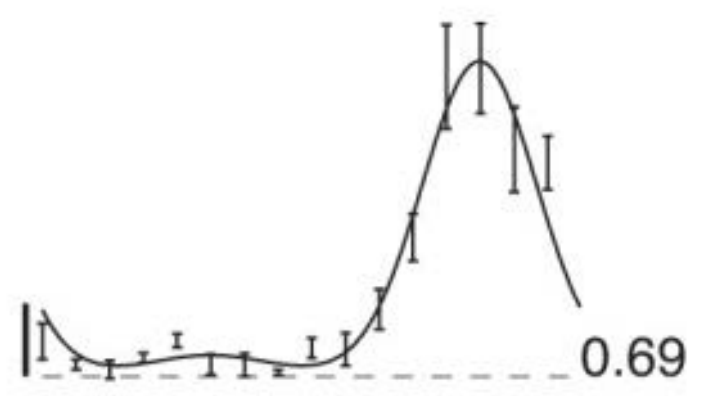

C

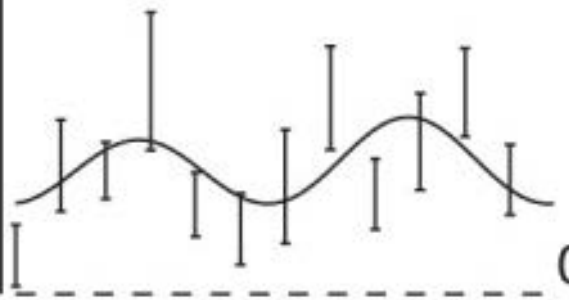

0.05

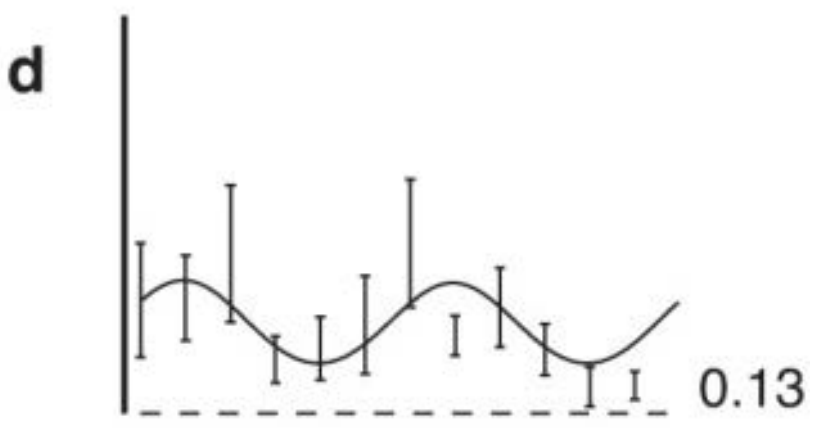

e

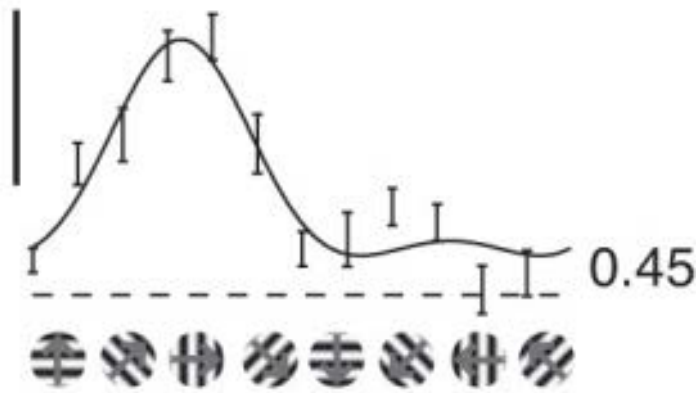


Laminar profile of direction selectivity in squirrel LGN and V1. Neurons from squirrel visual cortex exhibited weak direction selectivity index values, and LGN cells also exhibited weak direction selectivity. Left: laminar profile of 1 the circular variance in direction space index $(1-\mathrm{DICV})$ for the cortex as a function of depth and for the LGN as a function of layer. Right: example tuning curves of neurons $(a-e)$. In both the cortex and the LGN, very few neurons exhibited high direction selectivity. Numbers indicate 1 - DICV values.

Fig. 5.
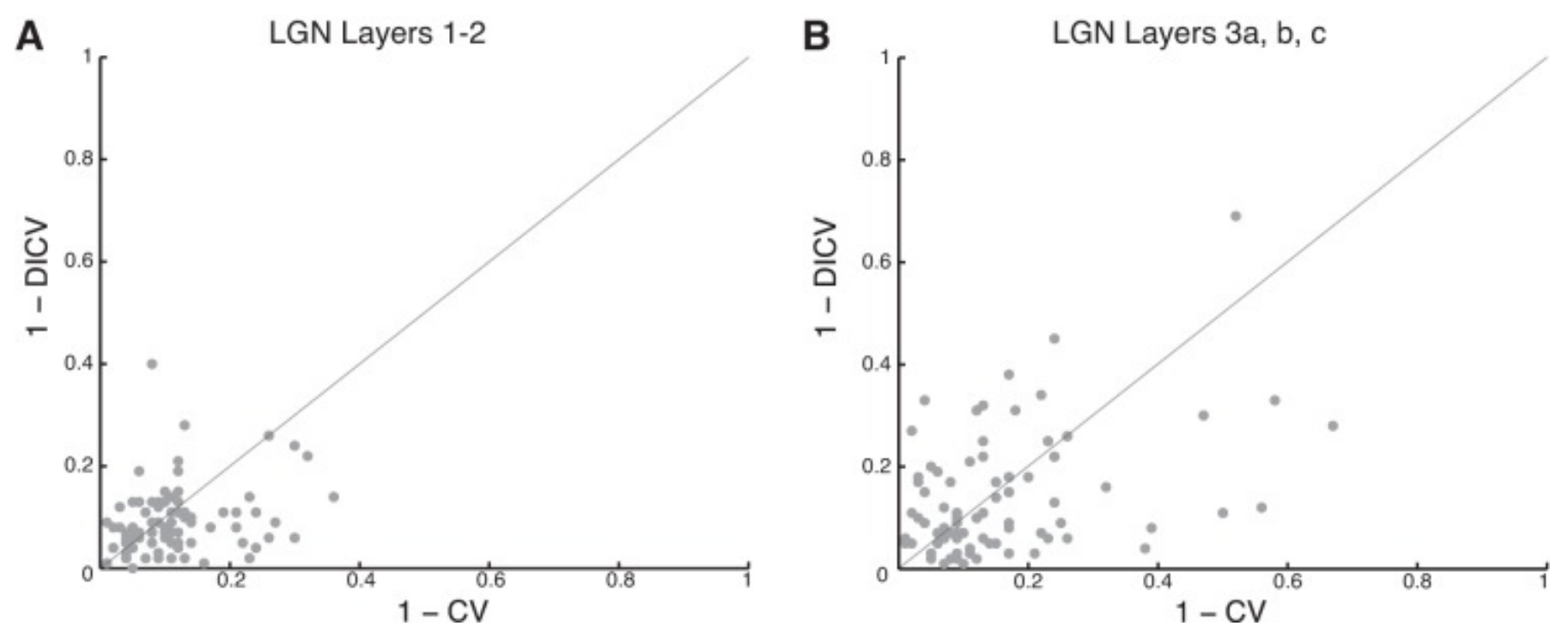

Orientation vs. direction selectivity for individual cells in squirrel LGN. A: plot of orientation selectivity index values ( $x$ axis) and direction selectivity index values ( $y$-axis) for cells in LGN layers 1-2. B: same for LGN layers 3abc. A wide variety of responses was observed, with some cells exhibiting moderate direction selectivity with weak orientation selectivity and vice versa.

Fig. 6.

A
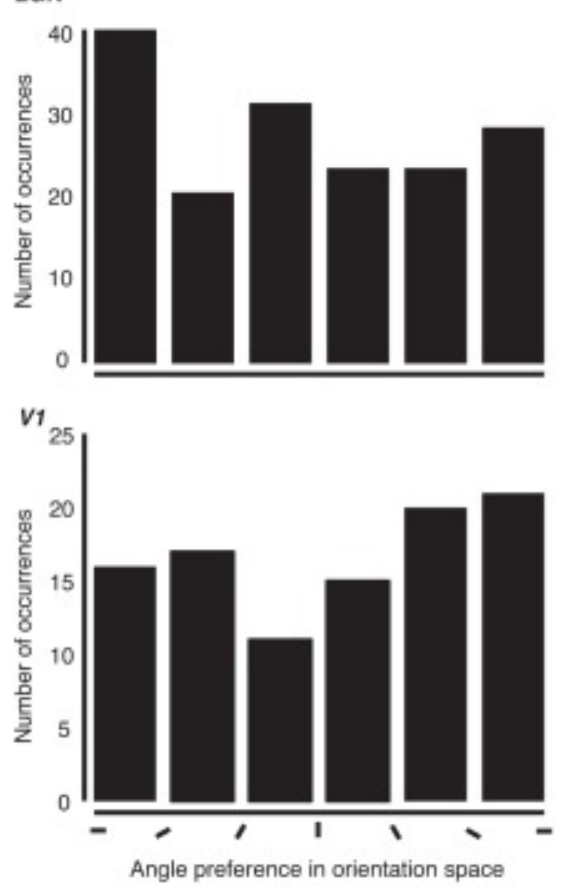

B

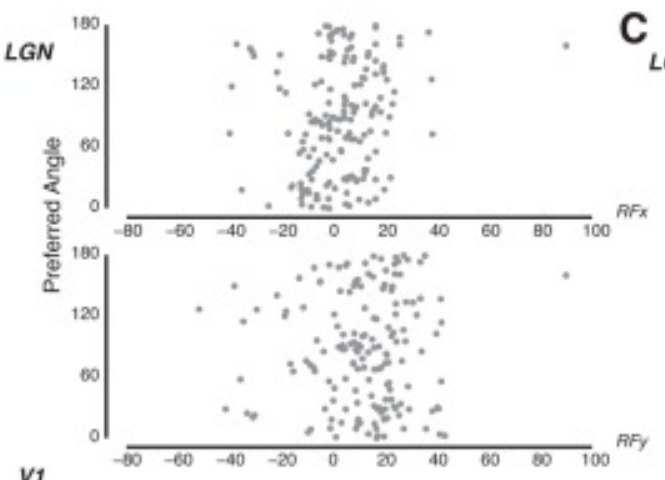

v1

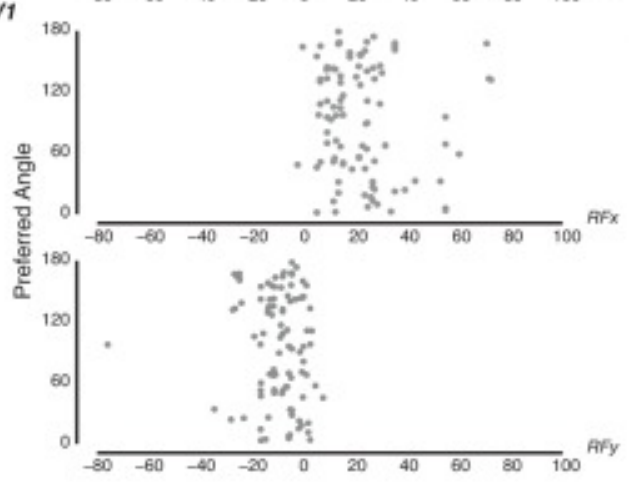

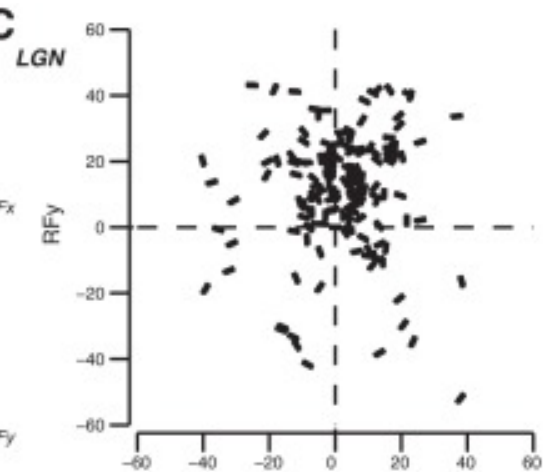

v1

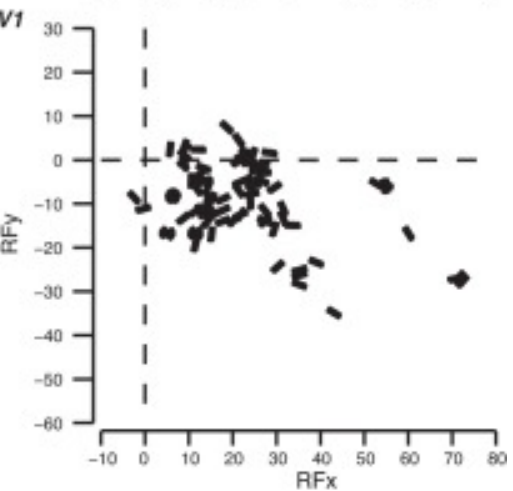


Lack of anisotropy of orientation preference. A: angle preference was evenly distributed in orientation space for cells in both the squirrel visual cortex and squirrel LGN ( $P>0.10$, Rayleigh test for nonuniformity of circular data). Bars indicate the angle values used for the histogram bin edges. $B$ : distributions of the preferred angle vs. $R F x$ and $R F y$ for cortex and LGN. No anisotropy with respect to receptive field location is evident. C: same, in 2-dimensional space, with orientation angle that gave the strongest response for each cell indicated with bar angle. No anisotropy near central vision is apparent. Multiple bars at single locations in V1 indicate perpendicular penetrations in visual cortex, where different orientation preferences were encountered owing to the lack of an orientation map in squirrel cortex (Heimel et al. 2005; Van Hooser et al. 2005). In this figure, $n=100$ cortical cells that had retinotopy data.

Fig. 7.
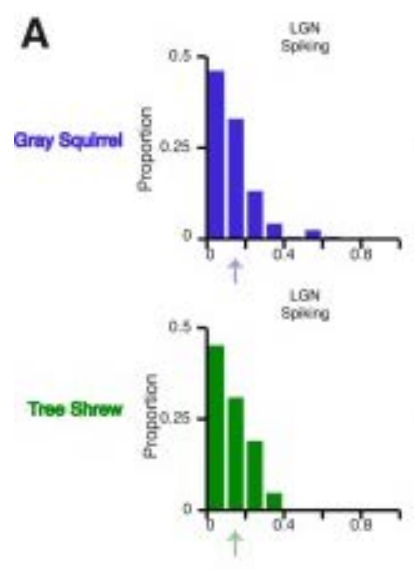

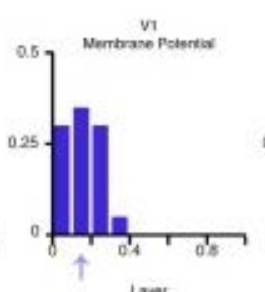

Loser

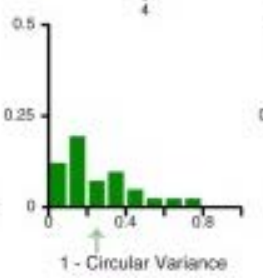

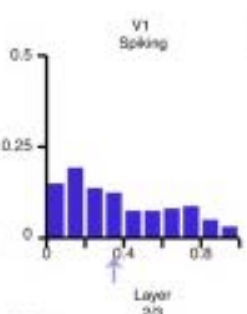

Laver

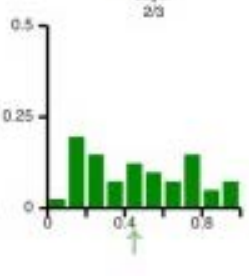

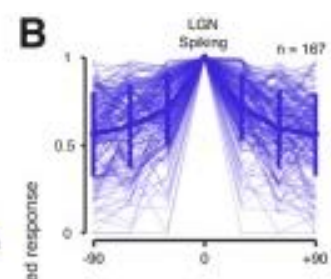
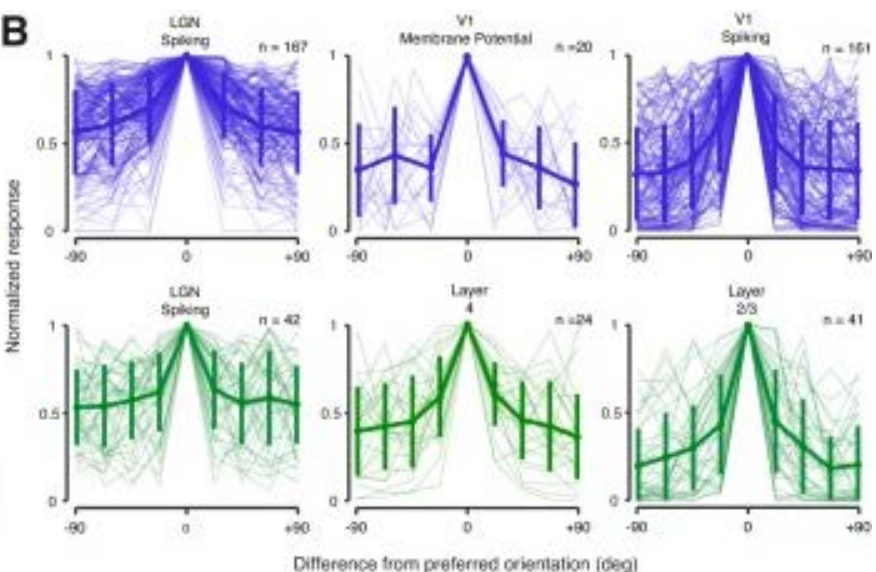

Comparison of orientation selectivity in the gray squirrel and tree shrew. A: histograms of orientation selectivity values $(1-C V)$ for gray squirrel: LGN (this study), V1 membrane potential (Van Hooser et al. 2006), and V1 extracellularly recorded spiking neurons (Van Hooser et al. 2005; Heimel et al. 2005). Arrows indicate means. Bottom plots: histograms of orientation selectivity for tree shrew LGN, V1 layer 4, and V1 layer 2/3 ( orientation tuning curves, normalized by the peak response at the preferred orientation, are shown centered around the preferred orientation $\left( \pm 90^{\circ}\right)$ are shown in the LGN and visual cortex for the gray squirrel (blue) and tree shrew (green). Means \pm SD are plotted over each population.

\section{Articles from Journal of Neurophysiology are provided here courtesy of American Physiological Society}

